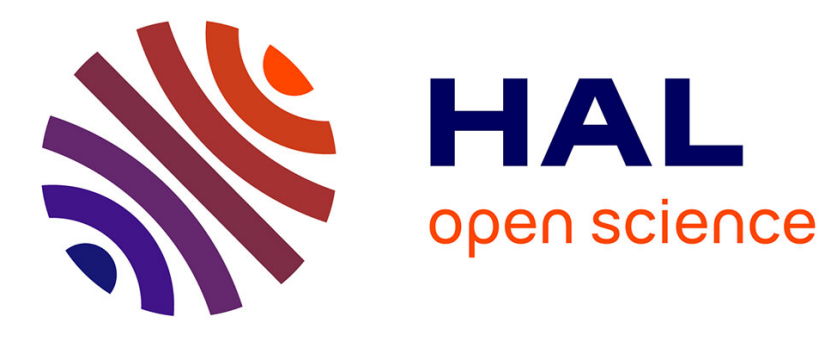

\title{
Evolution of chemical and thermal curvatures in thermoset-laminated composite plates during the fabrication process
}

Yasir Nawab, Frédéric Jacquemin, Pascal Casari, Nicolas Boyard, Vincent Sobotka

\section{To cite this version:}

Yasir Nawab, Frédéric Jacquemin, Pascal Casari, Nicolas Boyard, Vincent Sobotka. Evolution of chemical and thermal curvatures in thermoset-laminated composite plates during the fabrication process. Journal of Composite Materials, 2013, 47 (3), pp.327-339. 10.1177/0021998312440130 . hal01006825

\section{HAL Id: hal-01006825 \\ https://hal.science/hal-01006825}

Submitted on 1 Dec 2017

HAL is a multi-disciplinary open access archive for the deposit and dissemination of scientific research documents, whether they are published or not. The documents may come from teaching and research institutions in France or abroad, or from public or private research centers.
L'archive ouverte pluridisciplinaire HAL, est destinée au dépôt et à la diffusion de documents scientifiques de niveau recherche, publiés ou non, émanant des établissements d'enseignement et de recherche français ou étrangers, des laboratoires publics ou privés. 


\title{
Evolution of chemical and thermal curvatures in thermoset-laminated composite plates during the fabrication process
}

\author{
Yasir Nawab ${ }^{1,2}$, Frédéric Jaquemin', Pascal Casari', \\ Nicolas Boyard ${ }^{2}$ and Vincent Sobotka ${ }^{2}$
}

\begin{abstract}
Residual deformations and stresses formation in the thermoset-laminated composite is a frequently studied subject in the recent years. During fabrication, the laminated composites undergo chemical deformation during cross-linking and thermal deformation while cooling. In thin laminates, due to large displacements and complex evolution of shape, these deformations can only be explained by using nonlinear strain-displacement relationship. In the present article, we calculated together for the first time, the thermal and chemical deformations occurring in carbon/epoxy laminates by considering a nonlinear geometrical approach to understand the evolution of shape and hence residual stresses induced during fabrication process. The effect of fibre fraction on the chemical and thermal deformations is studied as well.
\end{abstract}

\section{Keywords}

Carbon/epoxy laminate, nonlinear geometrical behaviour, laminate theory, thermal/chemical curvature

\section{Introduction}

Residual deformation and stress induction in laminated composite has been studied by a number of authors. During the curing cycle, the thermoset composite undergoes residual strains and stresses due to mismatched coefficients of thermal expansion and chemical shrinkage of the constituents. These residual deformations and stresses depend mostly on the shrinkage behaviour of the polymer matrix, ${ }^{1}$ as fibres have no chemical and very small thermal shrinkage. The chemical shrinkage is a direct consequence of cross-linking of the thermosetting polymer. Resulting residual stresses can lead to dimensional instability, warpage, ply cracking, delamination and fibre buckling. ${ }^{2,3}$ Most of the authors ${ }^{4-8}$ studied the thermal residual deformations, and Hyer $^{8}$ was the pioneer to quantify and calculate the thermal deformations in the cross-ply laminates. Furthermore, some authors ${ }^{5,9}$ predicted the relatively complex final shapes of angular ply laminates. But none of them estimated the deformation in the laminated composite caused by chemical shrinkage as they assumed that piece is in stress-free state until complete cure. Bogetti and Gillespie ${ }^{10}$ showed that during a curing cycle, the composite undergoes chemical residual stress in addition to thermal stress. The chemical residual stress begins to appear in the composite during cross-linking due to chemical shrinkage. Modelling of shape of the piece and total residual stress $\sigma$ as a function of temperature $T$ and degree of cure $\alpha$ can be done by taking into account the chemical shrinkage as well as thermal expansion/contraction using an advanced form of Hooke's law (1).

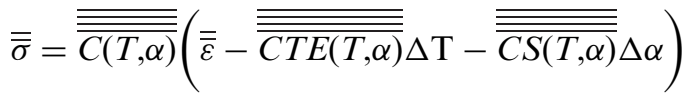

\footnotetext{
'Université de Nantes, Institut de Recherche en Génie Civil et Mécanique, UMR CNRS 6183, 37 boulevard de l'université, BP 406, Saint-Nazaire, France

${ }^{2}$ Université de Nantes, CNRS, Laboratoire de Thermocinétique de Nantes, UMR 6607, La Chantrerie, rue Christian Pauc, BP 50609, 44306, Nantes cedex 3, France
}

\section{Corresponding author:}

Frédéric Jaquemin, Université de Nantes, Institut de Recherche en Génie Civil et Mécanique, UMR CNRS 6183, 37 boulevard de I Université, BP406, 44600 Saint-Nazaire, France.

Email: frederic.jacquemin@univ-nantes.fr 
where $\varepsilon$ is the residual strain, which is calculated from the displacements. The rigidity matrix $C$, coefficient of thermal expansion (CTE) and coefficient of chemical shrinkage $(C S)$ depend linearly or not on the degree of cure $(\alpha)$ and temperature $(T)$. The coefficient of chemical shrinkage CS can be defined as 'change in dimension due to chemical shrinkage per unit initial dimension per change in degree of cure'. It has no unit and can be written mathematically as $C S=\frac{\Delta e_{\text {shrinkage }}}{e_{i} \Delta \alpha}$. Using the above formulation, Abou Msallem ${ }^{e_{i} \Delta \alpha}$ simulated the residual stresses and strains by assuming linear displacement-strain relations. In thin laminates, the displacement are very large with respect to thickness and evolution of the shape is complex so the linear straindisplacement relationship is not able to predict correctly the strain and hence the final shape of laminated piece ${ }^{12}$ so a nonlinear relationship is required.

In the present article, chemical deformations induced in the laminates are calculated for the first time using nonlinear strain-displacement relationship. This calculation is coupled with self-consistent model, which provided the thermo-physical properties of laminate, evolving with cure of resin. Thermal deformation is calculated as well and then the possible evolution of shape of composite piece during the curing cycle is presented. Moreover, the dependence of the deformations on fibre volume fraction is studied also.

\section{Calculation of strains}

For calculation of strains in the laminated plate, two approaches exist; linear approach or classical laminate theory and nonlinear one. Linear approach based on the linear strain-displacement is not able to predict correctly the deformation ${ }^{12}$ in a laminated piece. For example, room temperature shape of [0/90] unsymmetric laminates predicted by linear theory is 'saddle' like but in reality it is cylindrical. This difference was explained by assuming nonlinear strains-displacement relationship. ${ }^{13}$ According to nonlinear theory, the Von Karman simplified equations for nonlinear strains in term of displacement are written as:

$$
\text { Strain along x-axis } \varepsilon_{x x}=\frac{\partial u^{\circ}}{\partial x}-z\left(\frac{\partial^{2} w^{\circ}}{\partial x^{2}}\right)+\frac{1}{2}\left(\frac{\partial w^{\circ}}{\partial x}\right)^{2}
$$

Strain along y-axis $\varepsilon_{x x}=\frac{\partial u^{\circ}}{\partial x}-z\left(\frac{\partial^{2} w^{\circ}}{\partial x^{2}}\right)+\frac{1}{2}\left(\frac{\partial w^{\circ}}{\partial x}\right)^{2}$
Strain in $x-y$ plane or shear strain

$$
\gamma_{x y}=\frac{\partial u^{\circ}}{\partial x}+\frac{\partial v^{\circ}}{\partial y}-2 z\left(\frac{\partial^{2} w^{\circ}}{\partial x \partial y}\right)+\left(\frac{\partial w^{\circ}}{\partial x}\right)\left(\frac{\partial w^{\circ}}{\partial y}\right)
$$

Here $u^{\mathrm{o}}$ and $v^{\mathrm{o}}$ are the midplane displacements along $x$ - and $y$-axis, respectively, whereas $w^{\circ}$ is the out of plane, ${ }_{2}$ midplane displacement. The factors $\frac{1}{2}\left(\frac{\partial w^{\circ}}{\partial x}\right)^{2}$, $\frac{1}{2}\left(\frac{\partial w^{\circ}}{\partial y}\right)^{2}$ and $\left(\frac{\partial w^{\circ}}{\partial x}\right)\left(\frac{\partial w^{\circ}}{\partial y}\right)$ represent nonlinearity of strains along $x$-axis, $y$-axis and twist respectively. The value of $w^{\circ}$ is given in equation (5).

$$
w^{\circ}=-\frac{1}{2}\left(a x^{2}+b y^{2}+c x y\right)
$$

$a$ and $b$ are the curvature along $x$ and $y$ direction, whereas $c$ is the twist curvature. If the deformation is small then:

$$
a=-\left(\frac{\partial^{2} w^{\circ}}{\partial x^{2}}\right), \quad b=-\left(\frac{\partial^{2} w^{\circ}}{\partial y^{2}}\right), \quad c=-2\left(\frac{\partial w^{\circ}}{\partial x}\right)\left(\frac{\partial w^{\circ}}{\partial y}\right)
$$

The equations of strains are simplified by many authors. ${ }^{4,5,12,14}$ Gigliotti $^{12}$ solved the displacement equations using polynomial like Timoshenko's polynomial. It is one of the simplest ways that involves only five unknowns. But this method gives only the good results for [0/90] laminates. The midplane displacements by this method are:

$$
\begin{aligned}
& u^{\circ}=D_{1} x-\frac{1}{6} a^{2} x^{3}-\frac{1}{4} a b x y^{2} \\
& v^{\circ}=D_{2} y-\frac{1}{6} b^{2} y^{3}-\frac{1}{4} a b y x^{2}
\end{aligned}
$$

Here $D_{1}, D_{2}, a, b$ and $c$ are the coefficients to be determined. The twist curvature $c$ is zero in case of cross-ply laminates. To solve the equations of strains for angle ply as well as cross- ply laminates, Dano and Hyer $^{5}$ used richer equations (8) to (10) having 28 coefficients:

$$
\begin{aligned}
\varepsilon_{x}^{\circ}= & c_{00}+c_{10} x+c_{01} y+c_{20} x^{2}+c_{11} x y+c_{02} y^{2} \\
& +c_{30} x^{3}+c_{21} x^{2} y+c_{12} x y^{2}+c_{03} y^{3} \\
\varepsilon_{y}^{\circ}= & d_{00}+d_{10} x+d_{01} y+d_{20} x^{2}+d_{11} x y+d_{02} y^{2} \\
& +d_{30} x^{3}+d_{21} x^{2} y+d_{12} x y^{2}+d_{03} y^{3}
\end{aligned}
$$




$$
\begin{aligned}
\gamma_{x y}= & 2 e_{1}+\left(e_{2}+c_{01}\right) x+\left(e_{4}+d_{10}\right) y \\
& +\left(a b-\frac{c^{4}}{4}+2 c_{20}+2 d_{20}\right) x y+\frac{1}{2}\left(\left(\frac{a c}{2}+c_{11}\right) e_{3}\right) x^{2} \\
& +\frac{1}{2}\left(\left(\frac{b c}{2}+d_{11}\right) e_{5}\right) y^{2}+\left(3 c_{03}+d_{21}\right) x y^{2} \\
& +\left(3 d_{03}+c_{12}\right) y x^{2}+\frac{c_{21}}{3} x^{3}+\frac{d_{12}}{3} y^{3}
\end{aligned}
$$

Here $a, b, c, c_{00}, c_{10}, c_{01}, c_{20}, c_{11}, c_{02}, c_{30}, c_{21}, c_{12}, c_{03}$, $d_{00}, d_{10}, d_{01}, d_{20}, d_{11}, d_{02}, d_{30}, d_{21}, d_{12}, d_{03}, e_{1}, e_{2}, e_{3}, e_{4}$ and $e_{5}$ are the constants to be determined. Using these equations, they found the thermally deformed shapes of carbon/epoxy laminates for three groups of plies orientation $[-\theta /+\theta],[(90-\theta) / \theta],[(\theta-90) / \theta]$.

The total potential energy of laminated plate can be found from the known equation:

$$
E_{\mathrm{tot}}=\frac{1}{2} \sigma_{i j} \varepsilon_{i j}
$$

where $\sigma_{i j}$ is the residual stress field induced by the chemical cure shrinkage and thermal expansion/contraction, and $\varepsilon_{i j}$ is the strain field. By simplifying the potential energy expression for a plate having length $L_{x}$, width $L_{y}$ and thickness ' $z$ ' we get:

\section{Material properties}

\section{Fabrication cycle}

Carbon/epoxy-laminated composite [0/90] is considered for this study with three different fibre volume fractions $(30 \%, 43 \%$ and $57 \%)$, and $[+45 /-45]$ and $[+30 /-30]$ with $57 \%$ fibre volume. The dimensions of the piece studied are $190 \times 190 \times 1(\mathrm{~mm})$ with an equal number of plies of both angles in it. Following classical thermal curing cycle is selected for the study:

- Heating from room temperature $\left(20^{\circ} \mathrm{C}\right)$ to curing temperature $180^{\circ} \mathrm{C}$ at $3^{\circ} \mathrm{C} / \mathrm{min}$

- Maintaining at $180^{\circ} \mathrm{C}$ for $120 \mathrm{~min}$.

- Cooling to room temperature at $3^{\circ} \mathrm{C} / \mathrm{min}$.

In the first step, the resin undergoes chemical shrinkage and thermal expansion but as gel point is not reached yet, so material is not so rigid to undergo chemical deformation. During the second step, the resin undergoes cross-linking resulting into the chemical shrinkage of matrix and development of mechanical properties. As provided temperature is constant and due to small thickness of the part, exothermy due to the cross-linking does not impact the temperature, so the temperature remains constant, and chemical

$E_{\mathrm{tot}}=\int_{-\frac{L_{X}}{2}}^{\frac{L_{X}}{2}} \int_{-\frac{L y}{2}}^{\frac{L y}{2}} \int_{-\frac{z}{2}}^{\frac{z}{2}}\left[\begin{array}{c}\frac{1}{2} Q_{11}\left(\varepsilon_{x x}\right)^{2}+Q_{12}\left(\varepsilon_{y y}\right) \varepsilon_{x x}+Q_{16}\left(\varepsilon_{x y}\right) \varepsilon_{x x}+\frac{1}{2} Q_{22}\left(\varepsilon_{y y}\right)^{2}+Q_{26}\left(\gamma_{x y}\right) \varepsilon_{y y}+\frac{1}{2} Q_{66}\left(\gamma_{x y}\right) \varepsilon_{y y}-\left(Q_{11} C T E_{x x}\right. \\ \left.+Q_{26} C T E_{y y}+Q_{16} C T E_{x y}\right) \varepsilon_{x x} \Delta T-\left(Q_{12} C T E_{x x}+Q_{22} C T E_{y y}+Q_{26} C T E_{x y}\right) \varepsilon_{y y} \Delta T-\left(Q_{16} C T E_{x x}\right. \\ \left.+Q_{26} C S_{x y}\right) \varepsilon_{y y} \alpha-\left(Q_{16} C S_{x x}+Q_{26} C S_{y y}+Q_{x x} C S_{x y}\right) \gamma_{x y} \alpha\end{array}\right] \mathrm{d} x \mathrm{~d} y \mathrm{~d} z$.

$Q_{i j}$ are the elements of rigidity matrix.

By Lagrange-Dirichlet theorem, if total potential energy $\left(E_{\text {tot }}\right)$ is differentiated and value of first derivative is zero, then object will be in state of equilibrium

$$
\delta E_{\mathrm{tot}}=0
$$

In addition, this equilibrium will be stable if second derivative of total energy is definite and positive.

$$
\delta^{2} E_{\mathrm{tot}} \succ 0
$$

Evaluation of total energy at any instant using the equations (13) and (14) gives as by-product the curvatures of laminated plate subjected to chemical shrinkage and thermal expansion/contraction. shrinkage is the only prominent phenomenon in this step that caused the chemical deformation once the material passed the gel point. In the third step, the cured piece is cooled from curing temperature to room temperature resulting into thermal deformation. Thermal stress-free temperature is considered equal to curing temperature $\left(180^{\circ} \mathrm{C}\right)$.

\section{Self-consistent model for estimation of effective properties}

Self-consistent models based on the mathematical formalism proposed by Kroner ${ }^{15}$ and Eshelby ${ }^{16}$ constitute a reliable method to predict the micromechanical behaviour of heterogeneous materials, that is composites. In the present model, it was considered that fibres are the ellipsoidal inclusions embedded in an infinite 
medium called homogeneous effective medium. This medium is supposed to behave as a ply in the composite. The properties of this medium can be found by applying homogenization operations on the fibres and matrix. The material is investigated at two different scales for the needs of micromechanical modelling. The properties of the ply at macroscopic level, denoted using superscript ' $T$ ' are calculated from properties of fibres and matrix (microscopic level), which are denoted by ' $f$ ' and ' $m$ ', respectively. ${ }^{17}$

The microscopic and macroscopic residual stresses generated in the ply due to the temperature change and curing of resin can be found using the constitutive law (1). Eshelby demonstrated in his fundamental work that when the elementary inclusions (here the matrix and the fibre) were assumed to have ellipsoidal shapes, stresses and strains were related by the scale transition relation (15):

$$
\sigma^{r}-\sigma^{I}=-C^{I}: R^{I}:\left(\varepsilon^{r}-\varepsilon^{I}\right)
$$

Here ' $r$ ' stands for the constituent $\mathrm{f}$ or $\mathrm{m}$ means for fibre or matrix. $R^{I}$ is the reaction tensor and its value can be found by expression:

$$
R^{I}=\left(C^{I^{-1}}-E\right): E^{-1}
$$

$E$ is the Morris tensor that expresses the dependence of reaction tensor on morphology of constituents. As per the useful relation introduced by Hill, ${ }^{18}$ the macroscopic stresses and strains are equal to average of microscopic stresses and strains of constituents and can be expressed as:

$$
\begin{aligned}
& \left\langle\sigma^{r}\right\rangle_{\mathrm{r}=\mathrm{f}, \mathrm{m}}=\sigma^{I} \\
& \left\langle\varepsilon^{r}\right\rangle_{\mathrm{r}=\mathrm{f}, \mathrm{m}}=\varepsilon^{I}
\end{aligned}
$$

The self-consistent model allows determining the macroscopic elasticity tensor, coefficients of thermal expansion and chemical shrinkage of ply from the mechanical, thermal and chemical properties of the constituents. The relation (18) gives the classical expression of rigidity:

$$
C^{I}=\left\langle\left(C^{r}+C^{I}: R^{I}\right)^{-1}:\left(C^{I}+C^{I}: R^{I}\right): C^{r}\right\rangle_{\mathrm{r}=\mathrm{f}, \mathrm{m}}
$$

$C^{I}$ is determined by equation (18) using iterative method. The self-consistent model provides the homogenized coefficient of chemical shrinkage (equation (19)) and coefficient of thermal expansion (equation (20)). ${ }^{11}$

$$
\begin{aligned}
C S^{I} & =v^{m} C^{I^{-1}}\left\langle\left.\left(C^{r}+C^{I}: R^{I}\right)^{-1}\right|_{\mathrm{r}=\mathrm{f}, \mathrm{m}} ^{-1}\right. \\
& :\left(C^{m}+C^{I}: R^{I}\right)^{-1}: C^{m}: C \mathrm{~S}
\end{aligned}
$$

Table I Mechanical and thermo-mechanical properties of fibres

\begin{tabular}{llll}
\hline Property & Value & Property & Value \\
\hline$E_{1}(\mathrm{GPa})$ & 230 & $\mathrm{G}_{12}(\mathrm{GPa})$ & 27.6 \\
$E_{2}, E_{3}(\mathrm{GPa})$ & 20.7 & $\mathrm{CTE}_{1} \mathrm{~K}^{-1}$ & $-0.38 \times 10^{-5}$ \\
$v_{12}, v_{13}$ & 0.2 & $\mathrm{CTE}_{2} \mathrm{~K}^{-1}$ & $20 \times 10^{-6}$ \\
$G_{23}(\mathrm{GPa})$ & 6.89 & $\mathrm{CS}_{1}, \mathrm{CS}_{2}$ & 0 \\
\hline
\end{tabular}

CS: coefficient of chemical shrinkage; CTE: coefficient of thermal expansion.

Table 2. Effective properties of cured carbon/epoxy ply

\begin{tabular}{lccc}
\hline Property & 30 vol\% fibre & 43 vol\% fibre & 57 vol\% fibre \\
\hline $\mathrm{CTE}_{1}\left(\mathrm{~K}^{-1}\right)$ & $0.7 \times 10^{-6}$ & $0.4 \times 10^{-6}$ & $0.21 \times 10^{-6}$ \\
$\mathrm{CTE}_{2}\left(\mathrm{~K}^{-1}\right)$ & $42.3 \times 10^{-6}$ & $36.0 \times 10^{-6}$ & $29.8 \times 10^{-6}$ \\
$\mathrm{CS}_{1}(\%)$ & $-3.05 \times 10^{-2}$ & $-1.85 \times 10^{-2}$ & $-1.17 \times 10^{-2}$ \\
$\mathrm{CS}_{2}(\%)$ & -1.48 & -1.07 & -0.67 \\
$G_{12}(\mathrm{GPa})$ & 1.2 & 2.6 & 6.40 \\
$E_{1}(\mathrm{GPa})$ & 68.0 & 98.5 & 131.2 \\
$E_{2}(\mathrm{GPa})$ & 2.7 & 3.7 & 5.63 \\
$v_{12}$ & 0.30 & 0.27 & 0.25 \\
\hline
\end{tabular}

CS: coefficient of chemical shrinkage; CTE: coefficient of thermal expansion.

Similarly, the coefficient of thermal expansion can be found by equation (20)

$$
\begin{aligned}
C T E^{I}= & C^{I^{-1}}:\left\langle\left(C^{r}+C^{I}: R^{I}\right)^{-1}\right\rangle_{\mathrm{r}=\mathrm{f}, \mathrm{m}}^{-1} \\
& :\left\langle\left(C^{r}+C^{I}: R^{I}\right)^{-1}: C^{r}: C \mathrm{TE}^{r}\right\rangle_{\mathrm{r}=\mathrm{f}, \mathrm{m}}
\end{aligned}
$$

Table 1 shows the properties of fibres.

For the cured resin: Young modulus $E=1.37 \mathrm{GPa}$, Poisson ratio $v^{m}=0.35$, coefficient of thermal expansion $\mathrm{CTE}^{\mathrm{m}}=44.9 \times 10^{-6} \mathrm{~K}^{-1}$ and coefficient of chemical shrinkage $\mathrm{CS}^{\mathrm{m}}=0.019 .{ }^{19}$ Using the properties of cured resin and fibres, properties of composite were estimated by self-consistent model for three fibre volume fractions. These properties are presented in Table 2.

\section{Determination of thermal deformation}

\section{Cross-ply laminates}

Thermal curvatures induced in [0/90] carbon/epoxy laminate on cooling from curing temperature $180^{\circ} \mathrm{C}$ to room temperature are calculated by solving energy equations (12) to (14). Since the piece is thinner $(e=1 \mathrm{~mm})$, so it can be assumed that there are no temperature gradients. As composite supposed to be fully cured before cooling so $\Delta \alpha$ is zero in this step. 


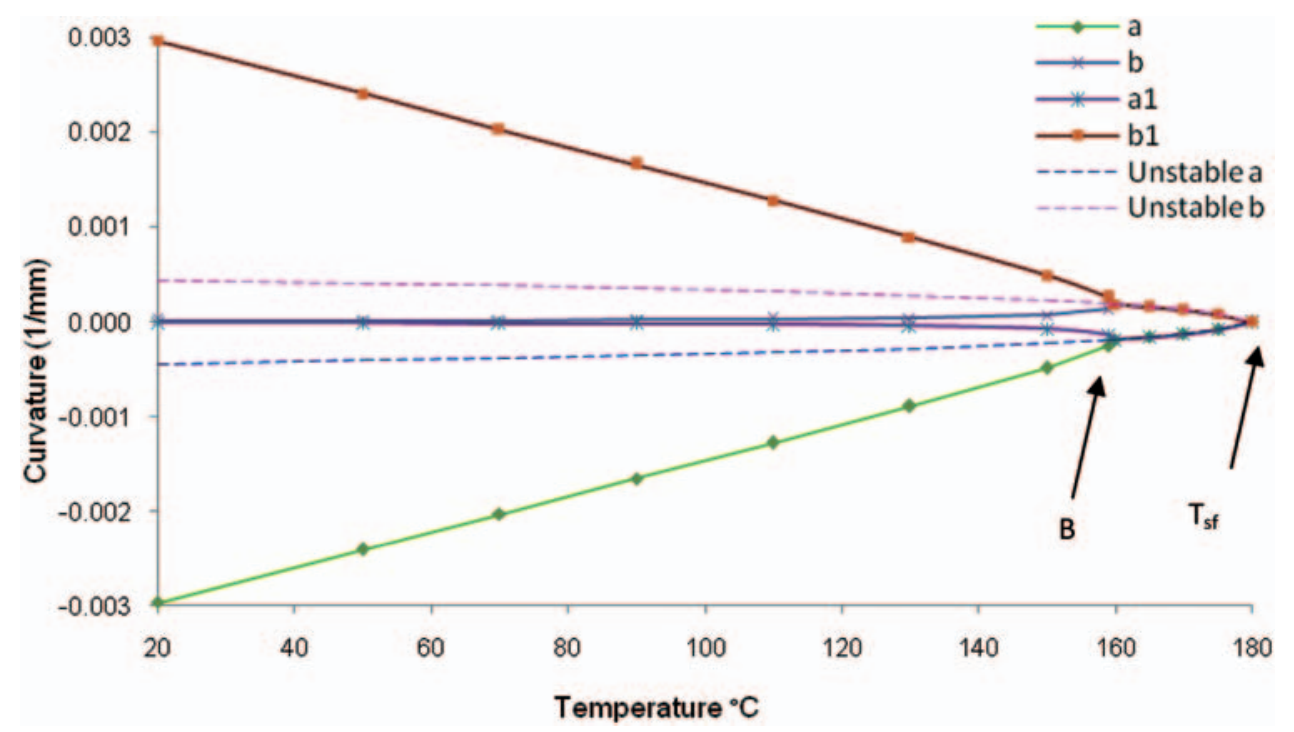

Figure I Thermal curvatures of [0/90] carbon/epoxy laminate.

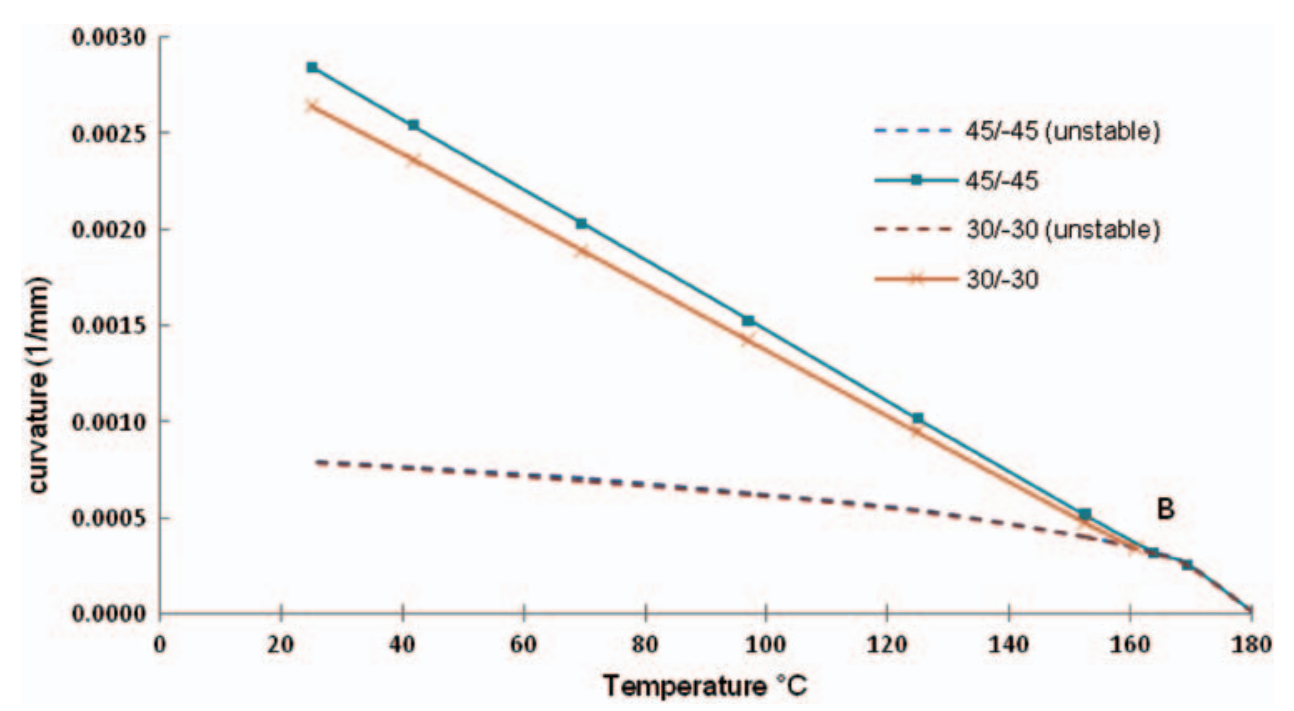

Figure 2. Thermal twist curvature ' $c$ ' of $[+/-45]$ and $[+/-30]$ laminates.

Equations (5) to (7), being simple equations, are used to calculate the strain fields. At first, curing temperature $180^{\circ} \mathrm{C}$ is assumed as thermal stress free temperature $\left(T_{\mathrm{sf}}\right)$ so the thermal deformation at this point is zero. Figure 1 shows the curvature in cross-ply laminated composite having $57 \%$ fibre volume fraction. On solving the energy equation (12), a saddle shape $(a=-b)$ is observed in the beginning. This pair of curves splits into three possible pairs of branches from the bifurcation point $(B)$; a saddle shape (dashed curves) and two cylinders $(a>0, b=0$ or vice versa) with axis along $x$ or $y$-axis. On verifying the three solutions using equations (13) and (14), it is found that saddle shape solution is not stable energetically after bifurcation point. So experimentally, only the cylindrical solutions are possible. The twist curvature ' $c$ ' in case of $[0 / 90]$ laminates is zero.

\section{Other stacking sequences}

In the previous section, thermal curvatures in [0/90], which is the simplest example of laminates, are discussed. Keeping in view the end use and properties required, the plies in laminate may be stacked at different orientations, for example $[+45 /-45],[+30 /-30]$. The final shape of these angle-ply laminates becomes more complex due to introduction of in-plane twist curvature ' $c$ ' in addition to ' $a$ ' and ' $b$ ' so equations (5), (8), (9) and (10) are used, as done by Hyer and Dano ${ }^{5}$, in order to calculate the curvatures. Figures 2 and 3 show 


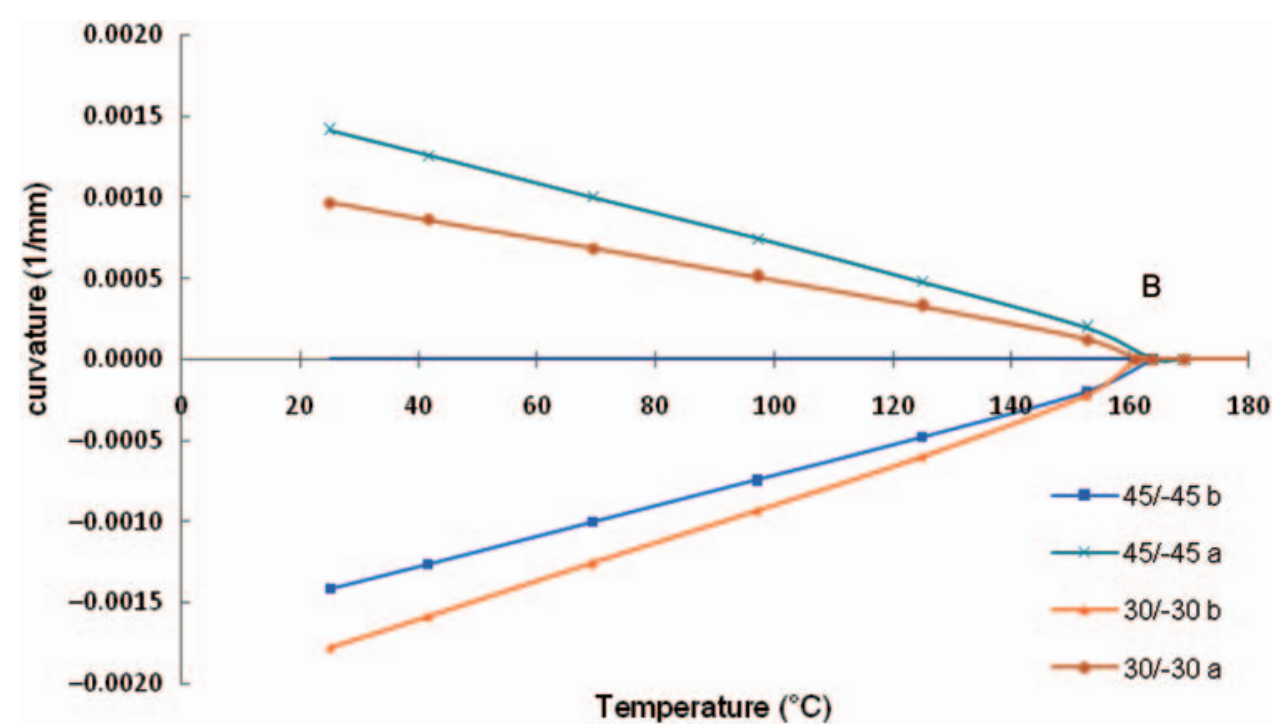

Figure 3. Thermal bending curvature of $[+/-30]$ and $[+/-45]$ laminates.

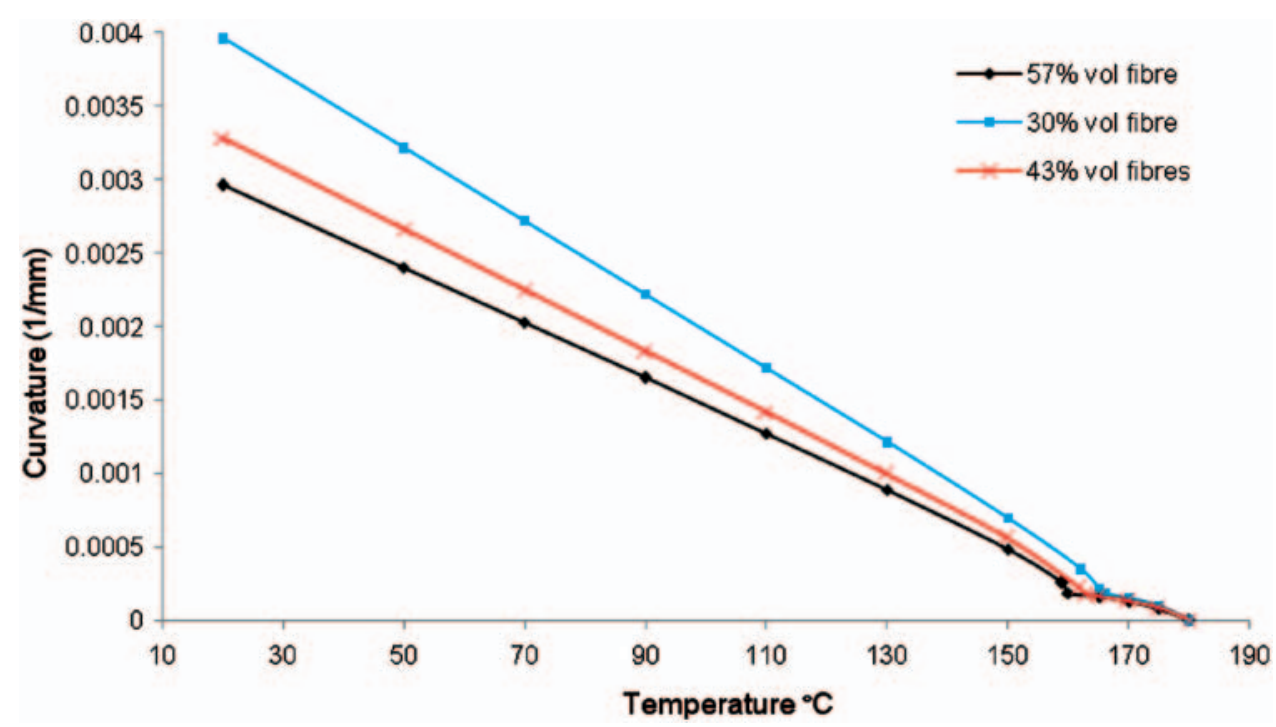

Figure 4. Thermal curvature ' $a$ ' for different fibre fractions.

the possible values of curvatures $a, b$ and $c$ for [ $+45 /$ $-45]$ and $[+30 /-30]$ calculated by using the properties of carbon/epoxy ply given in Table 2 for the same curing cycle used for [0/90]. It can be observed that during cooling from the stress-free temperature to bifurcation point ' $B$ ', there is only the twist in the laminate (Figure 2).

On further cooling, the twist curve splits into two branches; first one rise sharply and reaches maximum value at room temperature, whereas the second one increases slowly after the bifurcation point. Using the energy approach, it was found that the second solution is not stable. The bending curvatures (Figure 3) also appear from the bifurcation point ' $B$ ' resulting into two pairs of cylinders with curvatures increasing with cooling.

For \pm 45 laminated plate, the final shape is composed of two equal and opposite cylinders (shown by curvatures $a$ and $b$ ) with an in-plane twist ' $c$ '. For the \pm 30 laminated plate, final shape is also composed of two cylinders with an in-plane twist but these cylinders have not equal curvatures; one is bigger $(b)$ than the cylinder of \pm 45 and other is smaller $(a)$ than that of \pm 45 . The magnitude of twist ' $c$ ' is lower than the value computed for \pm 45 (Figure 2). Same technique can be used to simulate the curvature and twist of other orientations. 


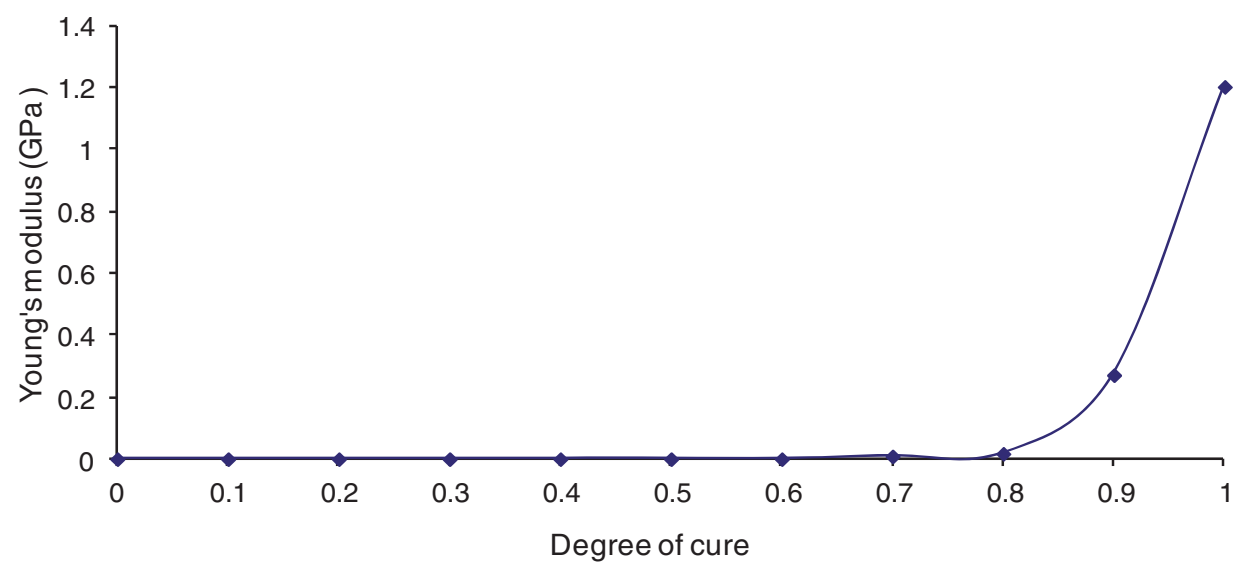

Figure 5. Variation of Young's modulus of resin with degree of cure.

\section{Dependence of thermal deformations on fibre volume fraction}

In order to study dependence of thermal curvatures induced in [0/90] on fibre volume fraction, these latter are drawn during cooling with respect to temperature using the properties shown in Table 2. In the Figure 4, only curvature ' $a$ ' are shown for better comprehension as corresponding curvatures ' $b$ ' are negligible. It is observed that final shape is cylinder like for all fibre fractions but curvature of deformed piece decreases with the increase in fibre volume fraction (Figure 4). In addition, a shifting of bifurcation point is observed. It is noted that bifurcation point of $30 \mathrm{vol} \%$ fibre is $165^{\circ} \mathrm{C}$, which decreases to $162^{\circ} \mathrm{C}$ and $159^{\circ} \mathrm{C}$ for $43 \%$ and $57 \mathrm{vol} \%$ fibre fractions, respectively. So, it can be concluded that by increasing the fibre fraction, the bifurcation temperature decreases.

\section{Chemical deformations}

As discussed earlier, the chemical deformation is an important factor that has not been taken into account yet for calculation of residual strain and stresses. In this section, the calculation of evolution of composite properties as function of degree of cure, and for a given fibre volume fraction is estimated using self-consistent model and then chemical curvatures are calculated by using these properties.

\section{Determination of effective properties during fabrication}

The properties of fibres, which were used for the estimation of composite properties, are given in the Table 1. As there is no chemical reaction in fibres during curing cycle, so their properties are independent of cross-linking, but properties of the resin are dependent on cure kinetics. Figure 5 shows the variation of
Young's modulus of the resin with degree of cure. It can be observed that Young's modulus of the resin is insignificant below $\alpha=0.8$ but from this point it increases sharply to reach a value of $1.37 \mathrm{GPa}$ in fully cured state. The gel point $\alpha_{\text {gel }}$ of the studied epoxy resin was found equal to $0.52 \pm 0.01$. The Poisson ratio $v^{m}$ of the resin is $0.35 .^{11}$

The cure shrinkage of the resin was determined experimentally and varies linearly with degree of cure. The slope of cure shrinkage-degree of cure graph gives the coefficient of chemical shrinkage $\left(\mathrm{CS}^{m}\right)$ of the resin, which was found equal to $-0.019 .{ }^{19}$

Using the properties of fibres and resin, the effective properties of composite during cross-linking are calculated for the $30 \%, 43 \%$ and $57 \%$ volume fraction of the fibres, and are shown in the Figure 6, 7 and 8.

Figure 6 shows the estimated coefficient of chemical shrinkage of composite along fibres $\left(\mathrm{CS}_{1}\right)$ and perpendicular to fibres $\left(\mathrm{CS}_{2}\right)$ for the three fibre fractions. It can be noted that the $\mathrm{CS}_{2}$ value increases by decreasing the fibre fractions, which is ultimately due to higher resin fraction. $\mathrm{CS}_{2}$ is negligible until $\alpha=0.5$ for $30 \%$ fibre volume and until $\alpha=0.6$ for $43 \%$ fibre volume. After this point, the $\mathrm{CS}_{2}$ coefficient increases sharply. Similarly for $57 \%$ fibre volume, the $\mathrm{CS}_{2}$ is not prominent until $\alpha=0.8$, but it rises sharply in the $\alpha$ range $[0.8,1]$. So it can be said that lesser the fibres are, lower the compactness of structure will be, and earlier the resin will overcome the fibre's opposition for sustaining their positions. The value of $\mathrm{CS}_{1}$ is negligible for the three cases, which means that the fibres block the resin shrinkage along them, and ultimate shrinkage of ply along fibres is negligible.

Figure 7 shows the transversal Young's modulus $\left(E_{2}\right)$ of a composite ply and Figure 8 shows in-plane coefficient of rigidity $\left(G_{12}\right)$ calculated from the properties of resin and fibres using self-consistent model.

Both moduli are drawn versus degree of cure. The values of $E_{2}$ and $G_{12}$ are higher for higher 


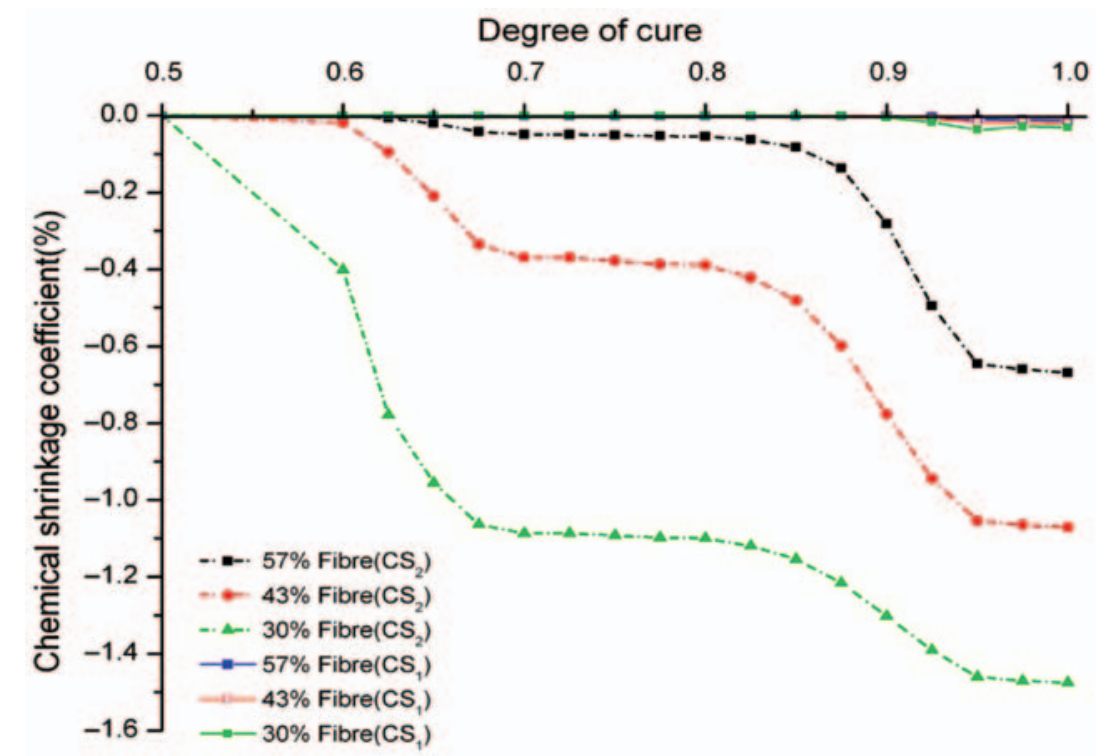

Figure 6. Effective coefficients of chemical shrinkage of composite.

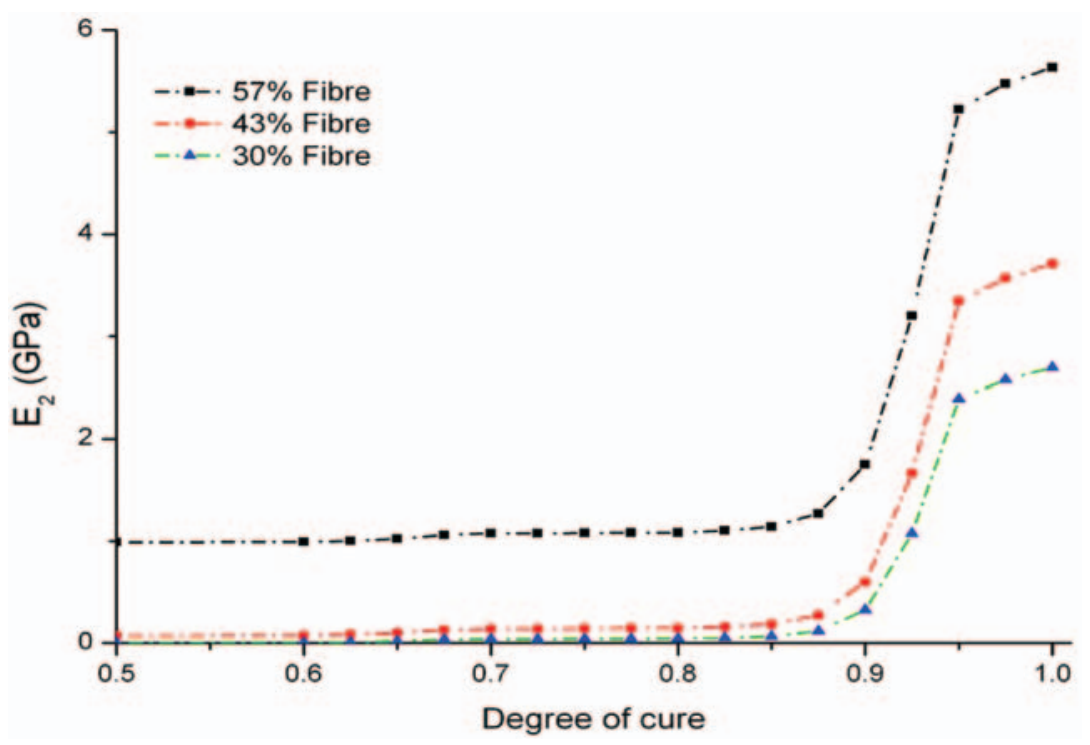

Figure 7. Effective elastic modulus of composite.

fibre fractions. They remain at rather constant values for a long range of $\alpha$ and then increases sharply from $\alpha=0.875$. For all fibre fractions, the longitudinal modulus $\left(E_{1}\right)$ is not much affected by the curing since fibre modulus is prominent in this direction. The values of $E_{1}$ were found constant while curing and can be seen in Table 2.

\section{Calculation of chemical curvatures}

Once the chemical and mechanical properties of composite laminates composite during curing are estimated, the energy equation is solved to get the curvatures due to chemical shrinkage. The degree of cure is calculated for our thermal cycle using the kinetics law $(21)^{19}$ as shown in Figure 9.

$$
\frac{\mathrm{d} \alpha}{d t}=K_{A}(T) \cdot G(\alpha) \cdot K_{D}\left(T_{g}(\alpha)\right)
$$

$G(\alpha)=\sum_{i=0}^{8} b_{i} \alpha^{i}$ is a function describing dependence of reaction rate on extent of reaction. $K(T)=$ $K_{\text {ref }} \exp \left[-A\left(\frac{T_{r e f}}{T}-1\right)\right]$ is the function that determines 


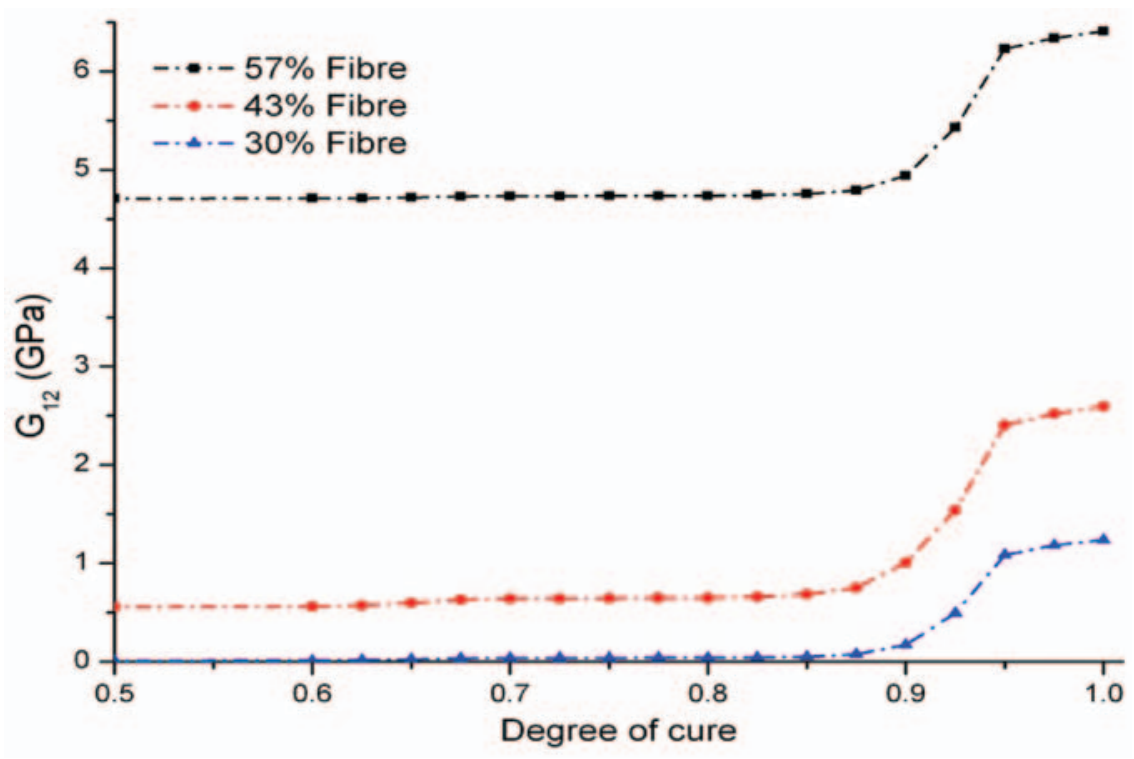

Figure 8. Effective shear modulus of composite.

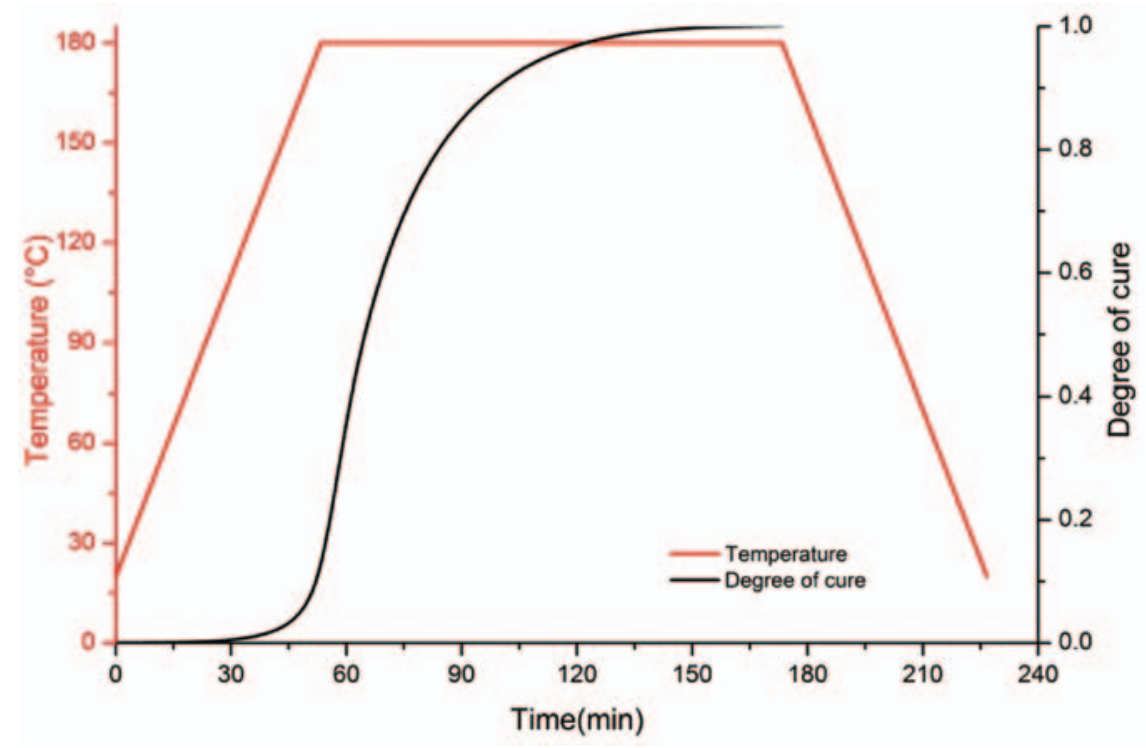

Figure 9. Degree of cure and temperature variation during the thermal cycle.

the dependence of reaction rate on temperature and $K_{D}(T)=K_{2} \operatorname{EXP}\left[C 1\left(\frac{T-T_{g}(\alpha)}{C_{2}+T-T_{g}(\alpha)}\right)\right]$ enables to take into account the effect of glass transition temperature $T_{\mathrm{g}}$ on diffusion of molecules and thus on reaction rate. All the parameter values are given in Abou Msallem et al. ${ }^{1}$

The chemical curing region of thermal cycle can be divided into two steps (Figure 9):

1. Heating step: temperature increases from room temperature to $180^{\circ} \mathrm{C}$ but no thermal or chemical deformations are expected to observe as properties of composite plies, that is Young's modulus, $\mathrm{CS}_{1}$ and $\mathrm{CS}_{2}$ are negligible.

2. Isothermal step: the temperature is constant so there is no thermal deformation, but due to chemical shrinkage of resin a chemical deformation is expected to appear.

- Figure 10 shows the estimated chemical curvatures while curing of $[0 / 90]$ laminate with $57 \%$ fibre volume fraction. As the properties of resin are negligible until gel point $\left(\alpha_{\text {gel }}=0.52\right)$, so no chemical curvatures are observed until this point. 


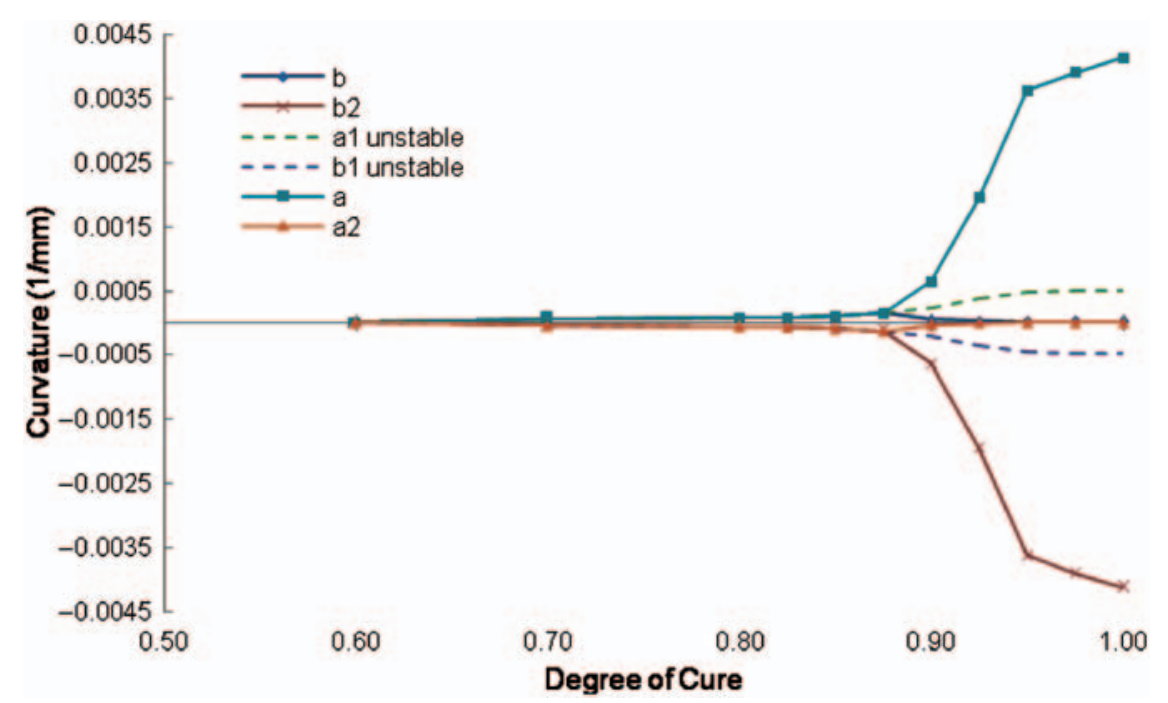

Figure 10. Chemical curvatures of composite $[0 / 90]$ as function of degree of cure.

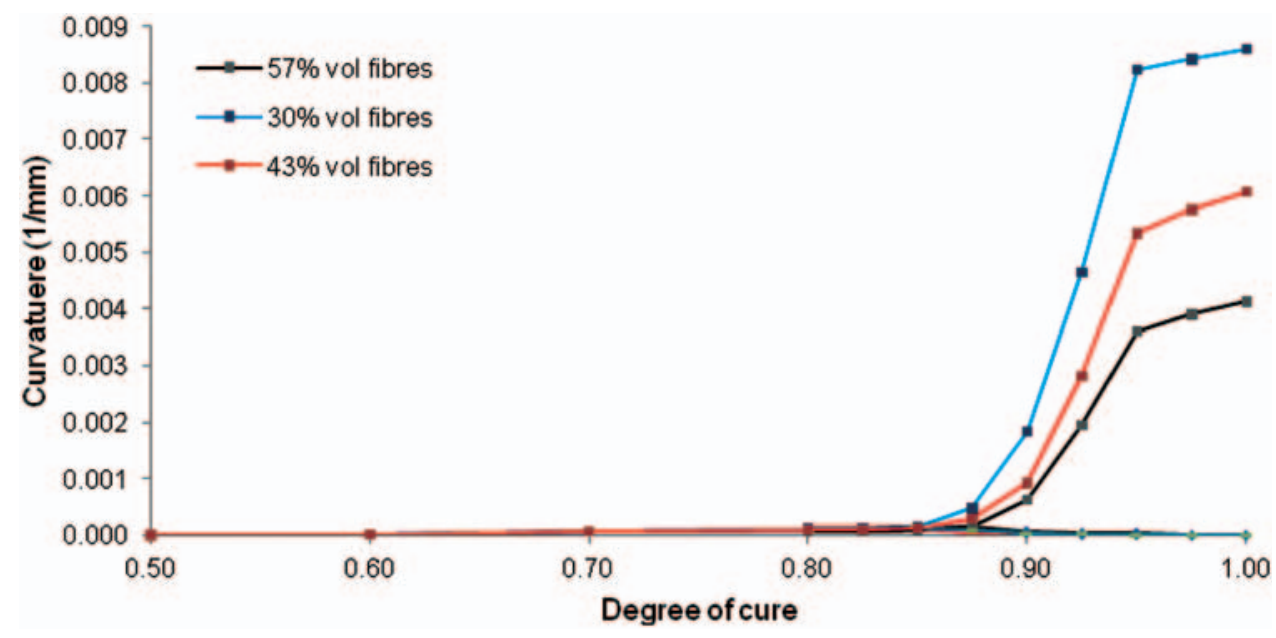

Figure II. Chemical curvatures for different fibre volume fractions.

- When the curvatures start to appear their magnitudes are not significant. Starting from $\alpha_{\text {gel }}$ to $\alpha=0.8$, two curvatures with equal but opposite magnitude are observed. This means that piece will deform in the saddle type shape but at $\alpha=0.875$ these curves separated into three pairs. So $\alpha=0.875$ is bifurcation point for this specific composite. From this point, there are three possible solutions. On verifying the stability of solutions by equation (14), the central pair (dashed curves) is found unstable. So in reality, a cylinder along $\mathrm{x}$ or $\mathrm{y}$-axis can be observed. The curvature of these cylindrical shapes increase with degree of cure until fully cured state. As explained earlier the mechanical properties of resin are negligible till $\alpha=0.8$ and it is not able to cause shrinkage of ply. But from this point the properties evolve sharply, and resin is able to induce shrinkage in ply.

That is why most of the deformation is observed after this point. Figure 11 shows the comparison of chemical curvatures of composite having $30 \%, 43 \%$, $57 \%$ fibre volume fraction.

It can be observed that curvature of $30 \%$ fibre volume fraction is more than that of $43 \%$ and $57 \%$. It seems realistic because only the resin is able to induce chemical deformation, if its quantity decreases, 


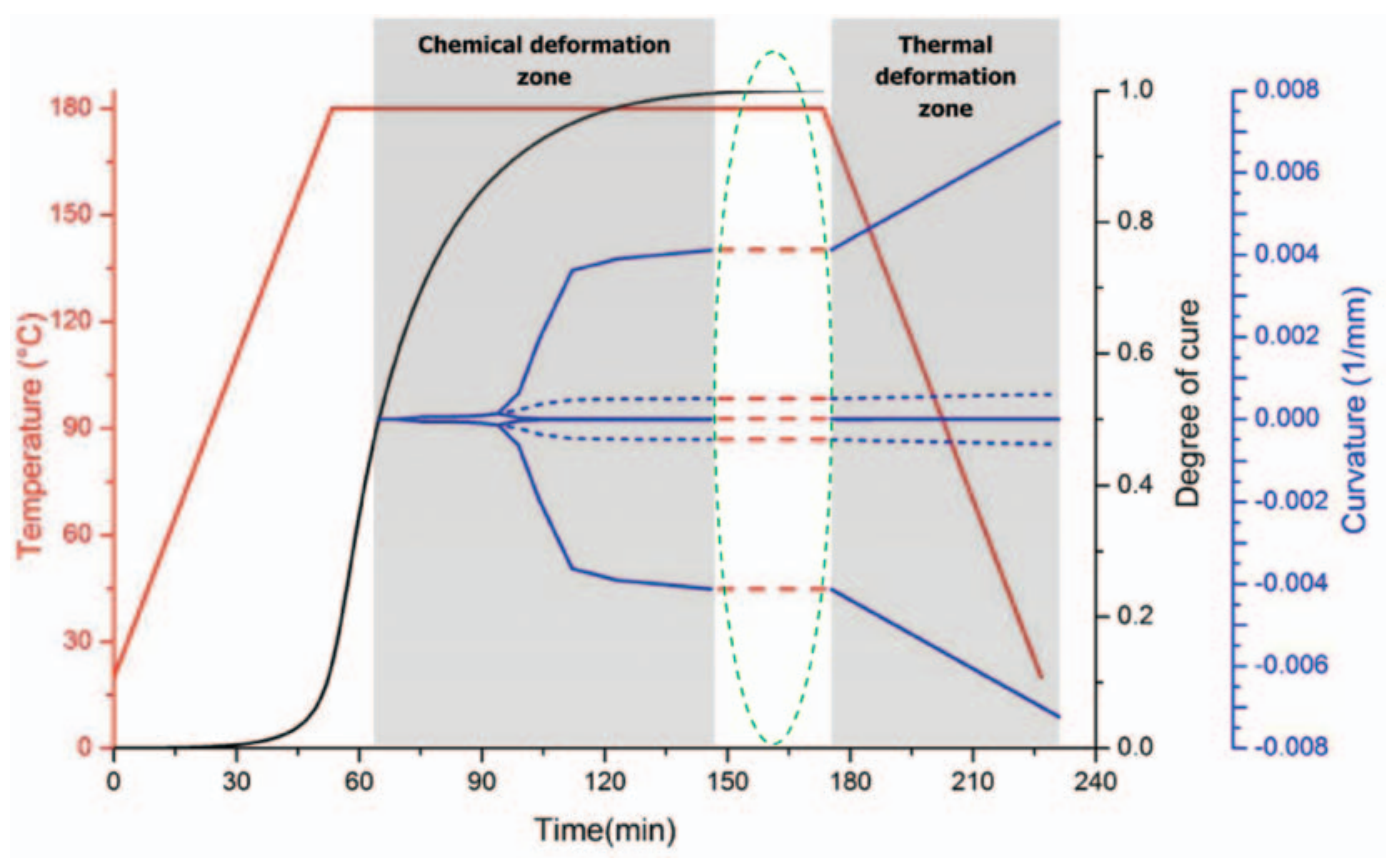

Figure I2. Shape evolution of [0/90] laminate without stress relaxation.

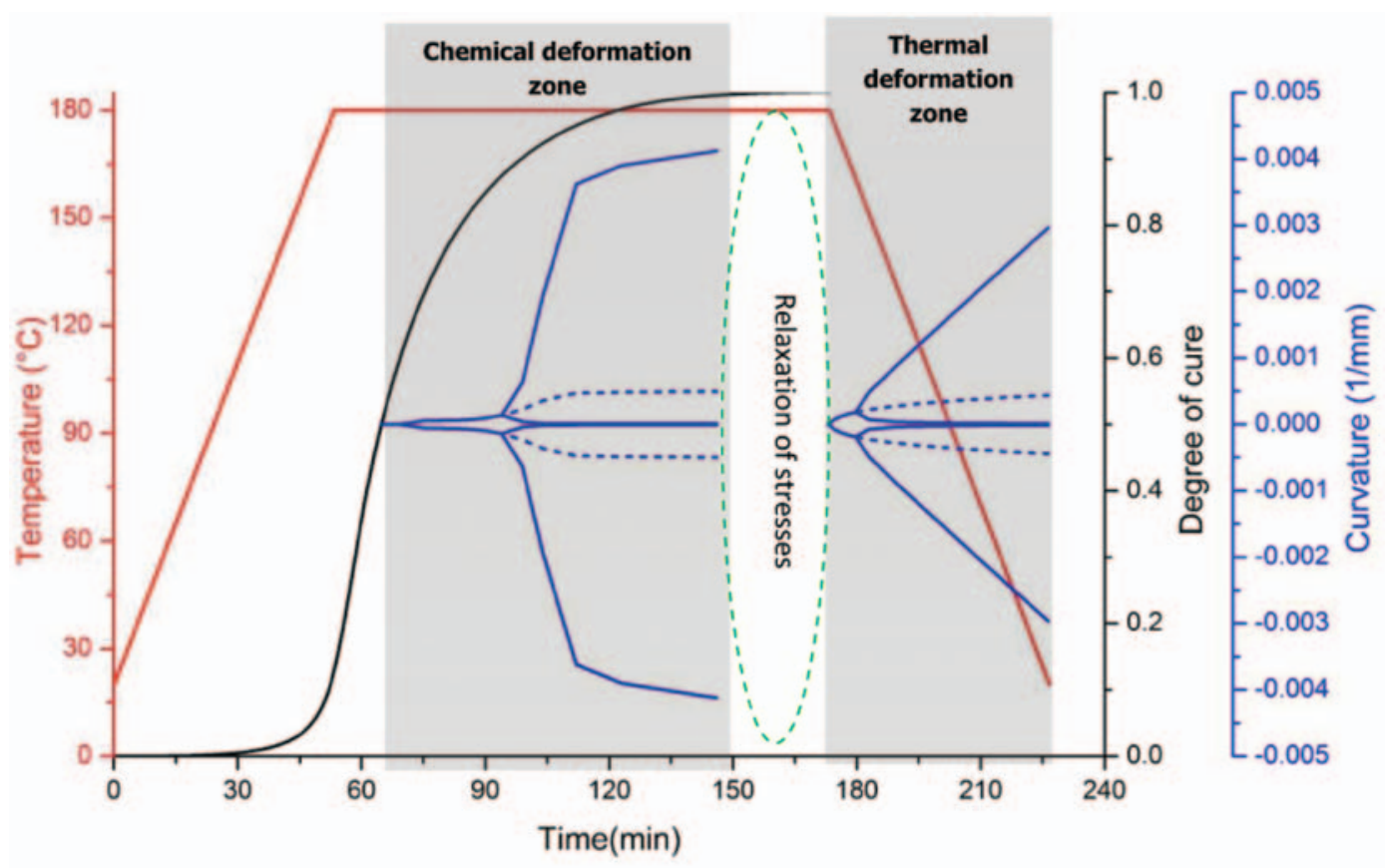

Figure 13. Shape evolution of [0/90] laminate with stress relaxation.

chemical curvature will decrease too. So it can be concluded that chemical curvature increases by decreasing the fibre volume fraction. Similarly a shift in bifurcation point is observed. Bifurcation point for $57 \%$ fibre is found at $\alpha=0.875$, which lowers to $\alpha=0.85$ and $\alpha=0.825$ for $43 \%$ and $30 \%$ fibre volume fractions, respectively.

\section{Evolution of curvature during the curing cycle}

Figure 12 shows the curvatures developed in 57 vol\% fibre composite due to chemical and thermal origin during the full curing cycle versus time. Temperature and degree of cure of resin are also presented on the same graph. 
All the short-dotted curves represent the unstable solutions of chemical and thermal curvatures. Chemical deformation zone $(\alpha=0.5$ to $\alpha=1)$ is also highlighted in the graph. In this zone, the piece deforms like a saddle in the beginning, but after the bifurcation point it converts into a cylinder. The maximum curvature is reached at $\alpha=1$. It can be noted that after the complete cure of resin (end of chemical deformation zone) there is a constant temperature zone ' $Z$ ' before the start of thermal deformation zone. This zone is very important to define the evolution of shape of laminated piece. It can be described in two possible ways

1. Zone ' $Z$ ' is short enough (highlighted by the dotted ellipse) to prevent any relaxation of stresses. Thus chemically deformed piece will maintain itself at maximum curvature till the beginning of thermal deformation zone (Figure 12). This continuation is plotted with the red dashed lines. The thermal curvature will appear at the beginning of thermal deformation zone and will result in the increase of curvature of chemically developed cylinder as shown in Figure 12.

2. The chemical stresses in the piece relax in zone ' $Z$ ', so the curvatures caused by chemical shrinkage disappear, and the thermal curvatures start from zero. Consequently, the piece deforms again in the saddle like shape and passing again through a bifurcation point it becomes a cylinder, whose curvature increases with cooling as shown in Figure 13.

The two simulations (Figures 12 and 13) have been conducted in order to get the extreme boundaries of the real physics of the phenomenon. The reality may lie within these boundaries, depending upon the stress relaxation. The magnitude of stress relaxation will be identified experimentally by following the shape of above mentioned unsymmetrical plates during and after curing. A suitable technique is a non-contact optical based method, that is fringe projection method. Moreover, evolution of mechanical properties of the composite material during cure must be measured experimentally in order to validate the results of selfconsistent model and to model accurately the behaviour of the structure. A work is in progress to tackle these tasks.

\section{Conclusion}

In this study, thermal and chemical deformations are predicted during the fabrication cycle of carbon/epoxy laminated composite, with various stacking sequences, considering the non-linear displacement-strain relationship. Effective properties of composite required for these calculations were estimated from the properties of matrix and fibres using self-consistent model. It is noted that the thermal and chemical deformation curvature decrease with increase in fibre volume fraction. A shift of bifurcation point for both types of deformations is also found with variation of fibre volume fraction. It is observed that chemical deformations begin to appear from gel point. If there is relaxation of residual stresses in zone $Z$ (constant temperature zone after complete chemical cure and before cooling), the chemical deformation become null before cooling, and thermal stresses start from zero. But if there is no relaxation in this zone, then chemical curvatures may cause significant increase in final deformation of the laminated piece. This study is a significant effort to understand fully the whole fabrication process, and a step towards establishing an experimental setup for the measurement of the chemical curvatures while curing. A work is already in progress.

\section{Funding}

This research received no specific grant from any funding agency in the public, commercial, or not-for-profit sectors.

\section{Conflict of Interest}

None declared.

\section{References}

1. Ruiz E and Trochu F. Numerical analysis of cure temperature and internal stresses in thin and thick RTM parts. Composites Part A 2005; 36: 806-826.

2. Wisnom MR, Gigliotti M, Ersoy N, et al. Mechanisms generating residual stresses and distortion during manufacture of polymer-matrix composite structures. Composites Part A 2006; 37: 522-529.

3. Sirivedin S, Fenner DN, Nath RB, et al. Matrix crack propagation criteria for model short-carbon fibre/epoxy composites. Compos Sci Technol 2000; 60: 2835-2847.

4. Peeters LJB, Powell PC and Warnet L. Thermally-induced shapes of unsymmetric laminates. J Compos Mater 1996; 30: 603-626.

5. Dano M-L and Hyer MW. Thermally-induced deformation behavior of unsymmetric laminates. Int J Solids Struct 1998; 35: 2101-2120.

6. Cho M and Roh HY. Non-linear analysis of the curved shapes of unsymmetric laminates accounting for slippage effects. Compos Sci Technol 2003; 63: 2265-2275.

7. Schlecht M, Schulte K and Hyer MW. Advanced calculation of the room-temperature shapes of thin unsymmetric composite laminates. Compos Struct 1995; 32: 627-633.

8. Hyer MW. Some observations on the cured shape of thin unsymmetric laminates. J Compos Mater 1981; 15: $175-194$.

9. Jun WJ and Hong CS. Cured shape of unsymmetric laminates with arbitrary lay-up angles. $J$ Reinf Plast Compos 1992; 11: 1352-1366. 
10. Bogetti TA and Gillespie JW. Process-induced stress and deformation in thick-section thermoset composite laminates. J Compos Mater 1992; 26: 626-660.

11. Abou Msallem Y, Jacquemin F and Poitou A. Residual stresses formation during the manufacturing process of epoxy matrix composites: resin yield stress and anisotropic chemical shrinkage. Int J Mater Form 2010; 3: 1363-1372.

12. Gigliotti M, Wisnom MR and Potter KD. Loss of bifurcation and multiple shapes of thin [0/90] unsymmetric composite plates subject to thermal stress. Compos $\mathrm{Sci}$ Technol 2004; 64: 109-128.

13. Lee SS and Hsu CS. Stability of saddle-like deformed configurations of plates and shallow shells. Int $J$ NonLinear Mech 1971; 6: 221-236.

14. Antonucci V, Cusano A, Giordano M, et al. Cureinduced residual strain build-up in a thermoset resin. Composites Part A 2006; 37: 592-601.
15. Kröner E. Berechnung der elastischen Konstanten des Vielkristalls aus den Konstanten des Einkristalls. $Z$ Phy A: Hadrons Nucl 1958; 151: 504-518.

16. Eshelby JD. The determination of the elastic field of an ellipsoidal inclusion, and related problems. Proc Roy Soc Lond Ser A Math Phys Sci 1957; 241: 376-396.

17. Jacquemin F, Freour S and Guillen R. A hygroelastic self-consistent model for fiber-reinforced composites. $J$ Reinf Plast Compos 2005; 24: 485-502.

18. Hill R. The essential structure of constitutive laws for metal composites and polycrystals. J Mech Phys Solids 1967; 15: 79-95.

19. Abou Msallem Y, Jacquemin F, Boyard N, et al. Material characterization and residual stresses simulation during the manufacturing process of epoxy matrix composites. Composites Part A 2010; 41: 108-115. 